\title{
Hacia un Sistema Integrado del Patrimonio Histórico de Andalucia: la base de datos del Patrimonio Inmueble
}

Valle Muñoz Cruz

Centro de Documentación del IAPH

\section{Resumen}

Se presenta la base de datos del Patrimonio Inmueble de Andalucía, primera fase del proceso de integración del Sistema de Información del Patrimonio Histórico de Andalucía (SIPHA). Se plantean los problemas de su sectorización y la necesidad de un único Sistema para la transferencia de instrumentos e información a la Administración. Se analizan los avances del Centro de Documentación en el diseño y desarrollo del SIPHA, las novedades de la aplicación de Patrimonio Inmueble y las implicaciones de su próxima implantación. Se concluye con los retos futuros del Sistema Integrado del Patrimonio Histórico.

\section{Palabras clave}

Sistemas de Información / Andalucía, Patrimonio Histórico / Patrimonio Inmueble / Bases de datos / Integración / SIPHA

La presentación de la Base de datos del Patrimonio Inmueble de Andalucía significa la culminación de una primera fase del trabajo realizado por el Centro de Documentación del IAPH para la integración de las diferentes bases de datos sectoriales que conforman el Sistema de Información del Patrimonio Histórico de Andalucía (SIPHA). Es la segunda experiencia de integración del Centro de Documentación, la elaboración del Tesauro del Patrimonio Histórico Andaluz (TPHA)' ya supuso un esfuerzo importante de integración de las distintas disciplinas patrimoniales y la apuesta por un único lenguaje documental para un Sistema de Información único.

El SIPHA es un proyecto marco de documentación e información que tiene como finalidad contribuir al conocimiento del Patrimonio Histórico para mejorar así, su gestión y tutela. El Sistema tiene como objetivos fundamentales: investigar y sistematizar la información de Patrimonio Histórico, transferir la información a distintos usuarios e integrar a diferentes organismos e instituciones productoras de información. ${ }^{2}$

Del análisis de la trayectoria del Centro de Documentación se observan dos grandes líneas de trabajo en la configuración del SIPHA. Desde el principio se trabaja en el desarrollo de la información del Patrimonio Histórico, se ponen en marcha diferentes bases de datos sectoriales que han ido cualificando el Sistema, ${ }^{3}$ se inicia la georreferenciación del Patrimonio Histórico y se elabora el Tesauro de Patrimonio Histórico. A partir de 1995 el Centro continúa la trayectoria ya iniciada y comienza su línea de transferencia de información a la sociedad en general y a la Administración en particular. Para ello se ponen en marcha distintos servicios de información, se crea el servidor Web del IAPH, se elaboran productos digitales y se realizan las primeras actuaciones para el desarrollo de la Red de información de Patrimonio Histórico, con el objetivo de descentralizar el SIPHA.

\section{El Sistema Integrado y la Red de Información del Patrimonio Histórico}

Los Sistemas de Información (SI) son instrumentos que posibilitan la adquisición, tratamiento y disponibilidad de la información y para ello se componen de elementos físicos (hardware), lógicos (software) y humanos. El SI de una organización tiene como finalidad lograr la integración de los flujos de información a través de distintos subsistemas de información, con objeto de mejorar la toma de decisiones desde las distintas áreas de la organización. En el caso del SIPHA el objetivo es lograr la integración de la información de la Gestión Patrimonial, información del Patrimonio Histórico, información Territorial e información Documental.

Las redes de información posibilitan la comunicación entre las diferentes áreas o departamentos de una organización o entre distintas organizaciones e instituciones. ${ }^{4}$ Este tipo de redes facilitan el acceso al SI de la organización, favorecen su descentralización pues permiten la carga y el acceso a la información desde los distintos puntos de la red, permiten compartir la información evitando su duplicación, contribuyendo así a un mejor aprovechamiento de los recursos humanos, materiales y económicos. ${ }^{5}$ Con la Red de Información del Patrimonio Histórico asistimos a la expansión del SIPHA, a su descentralización, a través de la red corporativa de la Junta de Andalucía, su canal de comunicación.

La Red de Patrimonio Histórico tiene una doble vertiente, por un lado contempla la implantación del SIPHA en los distintos organismos productores de información (DGBC, IAPH y DDPP), y, por otro lado, la creación de unidades de información en esos mismos organismos. 
El desarrollo de las bases de datos sectoriales cubría el objetivo inicial de contar con un registro de información sobre el Patrimonio Histórico de Andalucía. El paso siguiente era transferir esos instrumentos a las Delegaciones Provinciales y a la propia DGBC, con objeto de descentralizar tanto la carga como el acceso a la información. Las actuaciones realizadas por el Centro de Documentación en esta dirección 6 pusieron de manifiesto que la sectorización del Sistema, aunque necesaria en las fases iniciales de diseño y desarrollo, suponía importantes problemas, tales como:

- Compartimentación de la información de un mismo Bien por disciplinas patrimoniales o, lo que es lo mismo, duplicidad de registros en las bases de datos.

- Falta de normalización terminológica entre las distintas bases de datos.

- Problemas de funcionamiento al implantar aplicaciones diferentes en los organismos de Cultura.

- Falta de actualización de la información debido tanto a la sectorización del Sistema como a la inexistencia de un canal informático de comunicación, con consecuencias importantes para la gestión.

Ante esta situación se comienza a trabajar, desde 1996, en un Sistema Integrado, con el objetivo de solventar estos problemas y hacer posible la transferencia de información y conocimiento sobre el Patrimonio Histórico.

Las unidades de información de la Red del Patrimonio Histórico deberán desempeñar funciones similares a las del Centro de Documentación: colaborar en la configuración del Sistema de Información de la organización, a través del desarrollo del subsistema de gestión, la coordinación de la carga de información en el Sistema y la puesta en marcha de servicios de información internos y externos. Todo ello en coordinación con el Centro de Documentación. Hasta el momento se ha creado una unidad de información en la DGBC que funciona desde 1997.7 La implantación del SIPHA conlleva un importante cambio en el funcionamiento de la organización que deberá apoyarse en profesionales que, desde las unidades de información, coordinen y normalicen las actuaciones relacionadas con la producción y carga de información en el Sistema. La implementación, por tanto, del Sistema Integrado del Patrimonio Histórico debería ir paralela a la creación de estas unidades.

\section{Las Bases de Datos sectoriales del Patrimonio Histórico y la incorporación de los Sistemas de Información Geográfica}

El análisis de la trayectoria del Centro de Documentación en cuanto al diseño y desarrollo de aplicaciones informáticas para la configuración del SIPHA evidencia, por un lado, desarrollos sectoriales que han ido cualificando el Sistema, ampliando el objeto de estudio y las posibilidades de análisis del mismo y, pa- ralelamente, la implementación de aplicaciones para la integración de esos desarrollos parciales.

Partiendo de los cuatro subsistemas del SIPHA: Patrimonio Histórico, Territorio, Documentación y Gestión, en un principio el trabajo se centra en aplicaciones sectoriales cuyo ámbito de estudio es el bien inmueble o el bien mueble, el resultado son las bases de datos de Patrimonio Arquitectónico (SIBIA, 1993), 8 Patrimonio Arqueológico (ARQUEOS O DatARQUEOS, 1995), ${ }^{9}$ Patrimonio Etnológico (ETNO, 1997) ${ }^{10}$ y Patrimonio Mueble (Catálogo, 1993)."I A continuación se amplía el ámbito de análisis y desde el área de Patrimonio Arquitectónico y Urbano se diseña y desarrolla una aplicación de Conjuntos Históri$\cos (1998) .12$

Durante 1999, se implementan dos nuevas aplicaciones GeoARQUEOS 13 y ARQUEOSMapa, ${ }^{14}$ que incorporan los Sistemas de Información Geográfica y suponen un paso importante en la cualificación del Sistema. Se pone de manifiesto la necesidad de incorporar los avances logrados sectorialmente para el $\mathrm{Pa}$ trimonio Arqueológico, al conjunto del Patrimonio Histórico. La integración, por otro lado, de información alfanumérica e información cartográfica es la base para el desarrollo de una nueva línea de investigación basada en el análisis de las variables territoriales que inciden en el Patrimonio Histórico con objeto de evaluarlo, analizarlo y lograr así una gestión más eficaz de los Bienes Culturales por parte de las administraciones con competencias en Ordenación del Territorio y Patrimonio Histórico.

Durante el 2000 se desarrolla una aplicación de Ciudades Históricas de Andalucía ${ }^{15}$ que amplía de nuevo el ámbito de estudio desde los Conjuntos Históricos a las Ciudades Históricas e incorpora un visualizador a la aplicación, similar al de ARQUEOSMapa, que permite visualizar y realizar consultas sobre coberturas digitales, por último la aplicación, y esta es su novedad más importante, abría el abanico de posibilidades de estudio de la ciudad permitiendo el análisis de cualquier área urbana: Conjuntos Históricos, barrios, etc.

Paralelamente, en 1996 se forma un grupo de trabajo ${ }^{16}$ compuesto por representantes de las áreas temáticas del Centro, con el objetivo de lograr la integración de las distintas bases de datos sectoriales de Patrimonio Inmueble y Patrimonio Mueble, así se desarrolla el Prototipo de la Aplicación Integrada del Patrimonio Histórico ${ }^{17}$ (1999) que debe entenderse como un ensayo metodológico, la suma de aproximaciones sucesivas con errores y aciertos hacia un sistema único del Patrimonio Histórico de Andalucía. Sirvió para que los avances logrados se incorporaran progresivamente a los nuevos desarrollos sectoriales ${ }^{18}$, así como a la base de datos del Patrimonio Mueble19 (2000) y a la aplicación del Patrimonio Inmueble en Internet 20 (200 I).

Durante 2000-200 I se desarrolla una nueva aplicación de Ciudades Históricas de Andalucía²! en el 
marco del proyecto europeo de "Red de Centros Históricos de influencia islámica en el Sur de la Península Ibérica y Norte de Marruecos". Es la primera vez que dos Consejerías de la Junta de Andalucía realizan una iniciativa conjunta para integrar sus respectivos sistemas de información: el Sistema de Información Territorial (SIT) de la Consejería de Obras Públicas y Transportes y el Sistema de Información del Patrimonio Histórico de Andalucía (SIPHA), de la Consejería de Cultura. Con consecuencias sin duda importantes para la gestión del Patrimonio histórico y la ordenación del territorio. La nueva aplicación cualifica la anteriormente elaborada por el Centro e incluye también la base de datos integrada del Patrimonio Inmueble de Andalucía, la culminación del trabajo esbozado en el Prototipo de la Aplicación Integrada.

\section{La Base de Datos del Patrimonio Inmueble}

La nueva aplicación de Patrimonio Inmueble se ha desarrollado en Visual-Basic sobre Oracle, que es un gestor de bases de datos más potente e idóneo para el funcionamiento en red, 22 e incluye las siguientes novedades:

- Permite la consulta y la carga de información de todo el Patrimonio Inmueble de Andalucía: Patrimonio Arquitectónico, Arqueológico y Etnológico.

- Incorpora un visualizador cartográfico que integra información alfanumérica y cartográfica de todo el Patrimonio Inmueble de Andalucía 23 y que incluye con respecto a las anteriores aplicaciones nuevas prestaciones tales como: edición de coberturas, mejoras de las opciones de impresión y exportación e incorporación de nuevas coberturas.

- Está vinculada con la base de datos de Ciudades Históricas de Andalucía. Facilita la consulta, no sólo del Patrimonio Inmueble (elementos de interés) incluido en los límites de la Ciudad Histórica, sino también del existente en todo el término municipal.

- Se estructura en una serie de módulos de información comunes a todas las disciplinas patrimoniales y otros específicos, ${ }^{24}$ que permiten el análisis de un bien desde las distintas perspectivas patrimoniales. De esta manera se enriquece la información del Bien Cultural y se evita la duplicidad de registros de información (Figura I ).

- Incorpora el Tesauro de Patrimonio Histórico Andaluz, el lenguaje documental del SIPHA.

- Presenta un módulo de consulta común para Ciudades y Patrimonio Inmueble. Incluye un módulo básico de consulta y otro avanzado para consultas complejas.

- Facilita el acceso no sólo de los distintos organismos de Cultura: DGBC, IAPH y Delegaciones Provinciales, sino también de equipos externos colaboradores de Cultura. Para ello se ha elaborado una aplicación en Internet (Internet Aplication Server, IAS).
- El módulo de Administración permite la creación de distintos niveles de usuarios con acceso a determinadas funciones del Sistema: carga, consulta, validación, etc. La función de validación contribuirá a mejorar la calidad del Sistema de Información, a través de la revisión de la información cargada desde los distintos puntos de la Red, antes de su incorporación definitiva al Servidor Central.

La nueva aplicación incluye toda la información existente en las distintas bases de datos sectoriales. En concreto:

- Se han volcado alrededor de 3.800 registros de la base de datos de Patrimonio Arquitectónico (SIBIA) con información relativa a bienes inmuebles protegidos (Monumentos, Jardines Históricos, Sitios históricos y Lugares de interés etnológico) y considerados de interés. Las fuentes de información de todos estos registros son, entre otras, el Plan General de Bienes Culturales, BOJA, Expedientes de declaración, Fichas diagnóstico, Inventario de Cementerios, Catálogo del Movimiento Moderno, etc.

- Se han incluido unos 12.000 registros de yacimientos o unidades arqueológicas distribuidos por todo el territorio de Andalucía, procedentes de la base de datos de Patrimonio Arqueológico (ARQUEOS - DatARQUEOS). Las fuentes de información son fundamentalmente el Inventario de Yacimientos Arqueológicos de Andalucía, los expedientes para la inscripción de zonas Arqueológicas en el Catálogo General del Patrimonio Histórico de Andalucía y las intervenciones arqueológicas de la DGBC.

- Con respecto al Patrimonio Etnológico, se han volcado unos 3.500 registros de diferentes tipologías, como edificios industriales, agropecuarios, viviendas y espacios de sociabilidad, procedentes de la base de datos de Patrimonio Etnológico (ETNO). La fuente principal de información es el Inventario de Arquitectura Popular realizado por la DGBC que, en la actualidad, está en proceso de normalización.

- Por último, en relación con la documentación gráfica y cartográfica, se han incorporado a la aplicación imágenes digitalizadas del Patrimonio Inmueble y distintas coberturas temáticas de Patrimonio Histórico.

Módulos de Información de la Base de Datos de Patrimonio Inmueble

Módulos Comunes
Identificación-descripción
Localización
Planeamiento
Protección
Conservación-Intervención
A. Formal y físico constructivo
Información Bibliográfica
Información Documental
Información Gráfica

Módulos Específicos Análisis Funcional (Espacio) Análisis Funcional (Actividades) Intervenciones Arqueológicas 


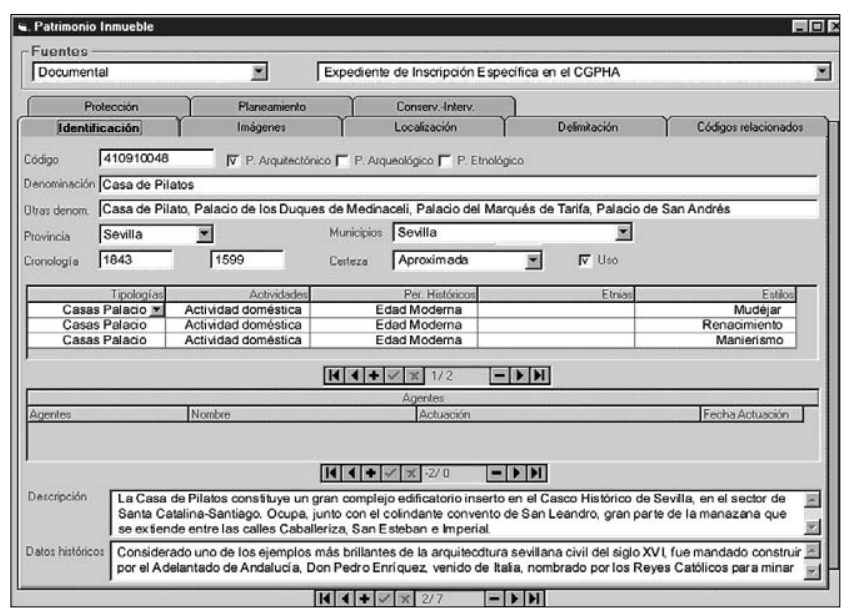

Fig. 2

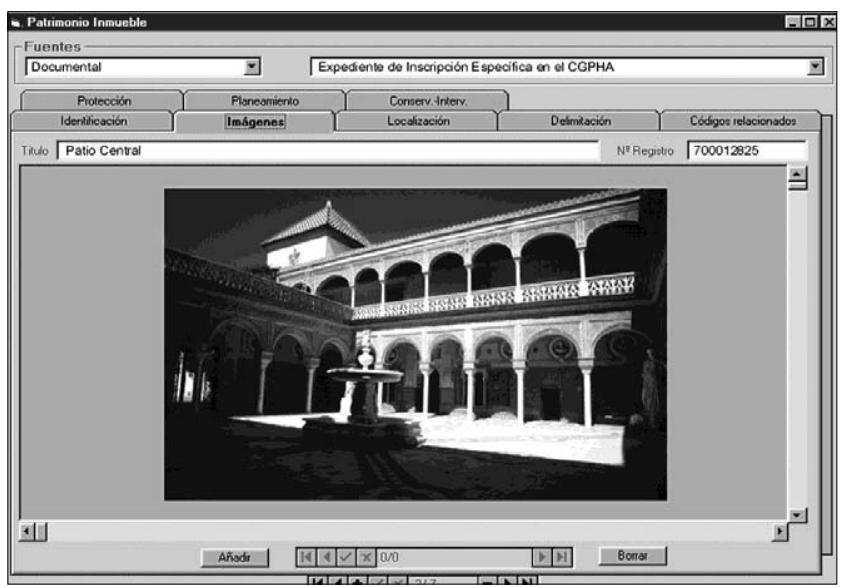

Fig. 4
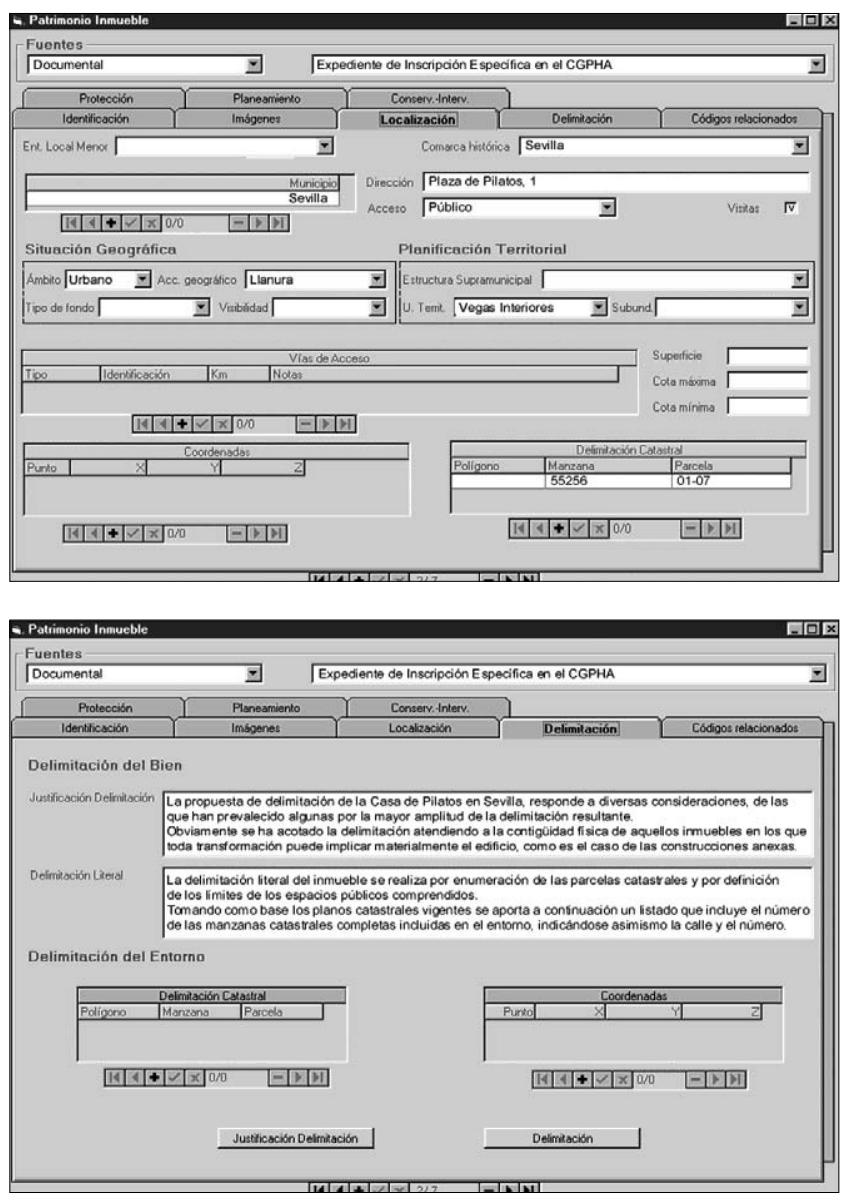

\section{Estructura de la base de datos}

La base de datos de Patrimonio Inmueble se estructura funcionalmente en un módulo de Altas/Modificaciones y otro de Consulta/Informes. El Módulo de ALTAS/MODIFICACIONES está organizado en los siguientes módulos de análisis.

El módulo de Identificación y descripción incluye los campos necesarios para la identificación y descripción de un inmueble desde cualquiera de las disciplinas patrimoniales: Patrimonio Arqueológico, Arquitectónico y Etnológico. El programa contempla que un mismo bien pueda analizarse desde cualquiera de estas disciplinas, activándose y desactivándose algunos campos en función de la caracterización seleccionada. En este módulo se incluyen datos tales como el código, denominación, provincia, municipio, tipologías, actividades, periodos históricos, estilos, etc. (Figura 2)

El módulo de Imágenes permite acceder a las imágenes digitales asociadas al inmueble, e incluye el título y el $n^{\circ}$ de registro de la imagen (Figura 3)

El módulo de Localización completa la información del módulo anterior incluyendo, por un lado datos administrativos (núcleo de población, otros municipios, etc.), información de la planificación territorial (unidades territoriales, estructuras urbanas supramunicipales, etc.), datos de ubicación (vías de acceso, coordenadas), etc. (Figura 4 )

El módulo de Delimitación, recoge información sobre la delimitación del bien y del entorno. Incluye campos como la justificación de la delimitación y la delimitación literal, y en el caso del entorno, datos relacionados con su localización: polígono, manzana y coordenadas (Figura 5)

El módulo de Códigos relacionados permite establecer relaciones de tipo jerárquico y asociativo entre los registros de la base de datos. Por ejemplo, relaciones jerárquicas entre una parte de un inmueble y el inmueble y relaciones asociativas entre edificios que presenten características comunes.

El módulo de Protección incluye información relativa al estado de tramitación (incoado, declarado, inscrito), figura de protección (BIC, Catálogo General, etc.), y tipología jurídica, junto con información relacionada con la disposición y su publicación, justificación de la protección, instrucciones particulares, titularidad, etc. (Figura 6)

El módulo de Planeamiento es muy similar al de Ciudades Históricas, presenta una primera parte con campos que identifican las distintas figuras de planeamiento que afectan al inmueble objeto de análisis, tales como clase, figura, denominación, estado tramitación, convalidación por Cultura, disposición, etc.; y una segunda parte con campos referentes a la protección del inmueble desde el planeamiento urbanístico: catálogo, ámbito, denominación, nivel de protección y definición del nivel y determinaciones del planeamiento sobre el inmueble (Figura 7) 
El módulo de Conservación-Intervención, consta de dos apartados, el primero recoge unos datos generales de Conservación (estado de conservación, factores de alteración, medidas adoptadas, etc.), a continuación permite un análisis de conservación por unidades funcionales del inmueble (este análisis sólo es válido para el Patrimonio Arquitectónico y Etnológico). El segundo apartado incluye los datos de las intervenciones realizadas al inmueble: título proyecto, tipo de intervención, fecha, descripción, agente, etc. (Figura 8)

Por último el módulo Documentación, presenta tres submódulos de Información bibliográfica, documental y gráfica, que incluye los datos básicos de identificación de los documentos relacionados con el inmueble analizado. Estos módulos son una versión reducida de las bases de datos documentales del Centro de Documentación.

Con respecto al módulo de CONSULTAS/INFORMES presenta una pantalla común para Ciudades ${ }^{25}$ y Patrimonio Inmueble que permite realizar una consulta de tipo territorial o ir acotando la consulta a través de un encuadre territorial (Figura 9). Una vez realizado el encuadre territorial puede optarse por realizar una consulta más específica de Ciudades o Patrimonio Inmueble. En el caso del Patrimonio Inmueble la aplicación incluye dos opciones: búsquedas libres o búsquedas predeterminadas. Búsquedas libres permite al usuario seleccionar libremente los campos y términos por los que desee realizar la consulta. Búsquedas predeterminadas, presentan una serie de opciones fijas que responden a aquellas peticiones o consultas tipo más frecuentes en el servicio de información (búsqueda geográfica, tipología jurídica, protección, etc.)

En el caso de Búsquedas libres habrá dos modalidades, una para búsquedas básicas y sencillas y otra para búsquedas de tipo avanzado. La aplicación incluye un formulario de consulta común para las tres caracterizaciones (Figura 10) y formularios específicos para cada una de ellas.

Con respecto a la recuperación de la información, el resultado de la búsqueda realizada se puede visualizar a través de un listado y también es posible ver los datos de los registros seleccionados. Por último, la base de datos dispone de distintos modelos de listados e informes (básicos y completos) de acuerdo con las necesidades detectadas en las áreas temáticas y el servicio de información del Centro de Documentación.

\section{Implicaciones de la nueva aplicación}

La implantación de la base de datos integrada y el trabajo en red desde los distintos organismos de Cultura supone importantes cambios a nivel organizativo y metodológico. El proceso de integración se refiere a instrumentos, herramientas, información y finalmente formas y modos de trabajar que aporten al Sistema información actualizada y de calidad.

El proceso se concibe de forma progresiva, tras un periodo de prueba en el IAPH se realizará su instala- ción en un Servicio de la DGBC y una Delegación Provincial, una vez superada esta fase experimental, se procederá a su implantación en el resto de Servicios de la DGBC y Delegaciones Provinciales.

Todas estas actuaciones tienen importantes implicaciones técnicas y humanas. Desde un punto de vista técnico es necesaria la coordinación con el Servicio de Informática para que todos los puntos de la red cuenten con acceso a la red corporativa de la Junta de Andalucía, así como con el gestor de bases de datos Oracle. En cuanto al equipamiento, del estudio realizado en el año 2000 para la puesta en marcha de la Red de Información ${ }^{26}$ se detectaron deficiencias en cuanto al equipamiento de las Delegaciones Provinciales y de la DGBC que deberán subsanarse antes de la implantación.
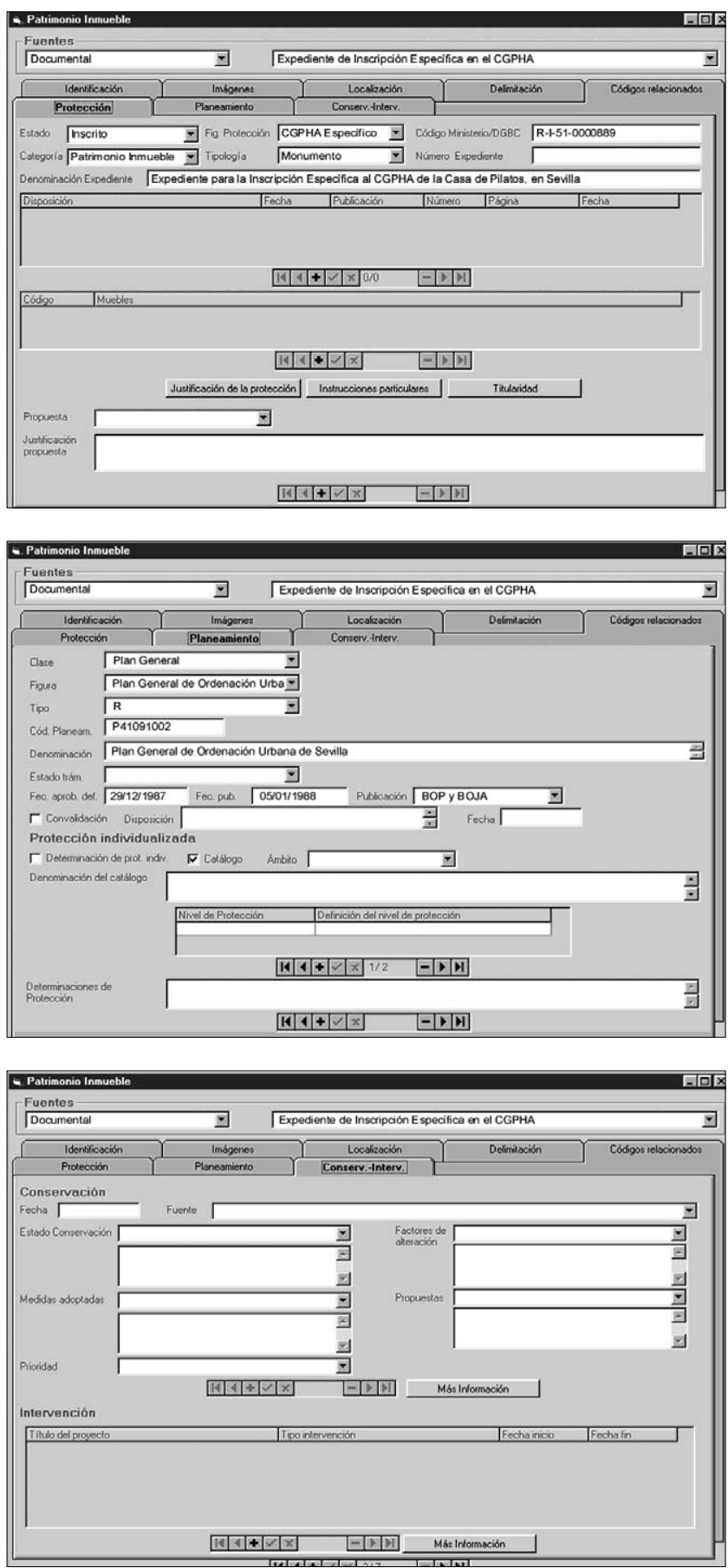


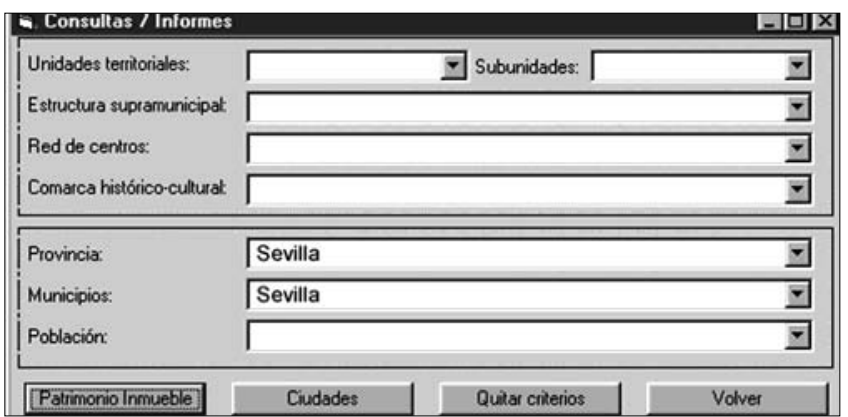

Fig. 9

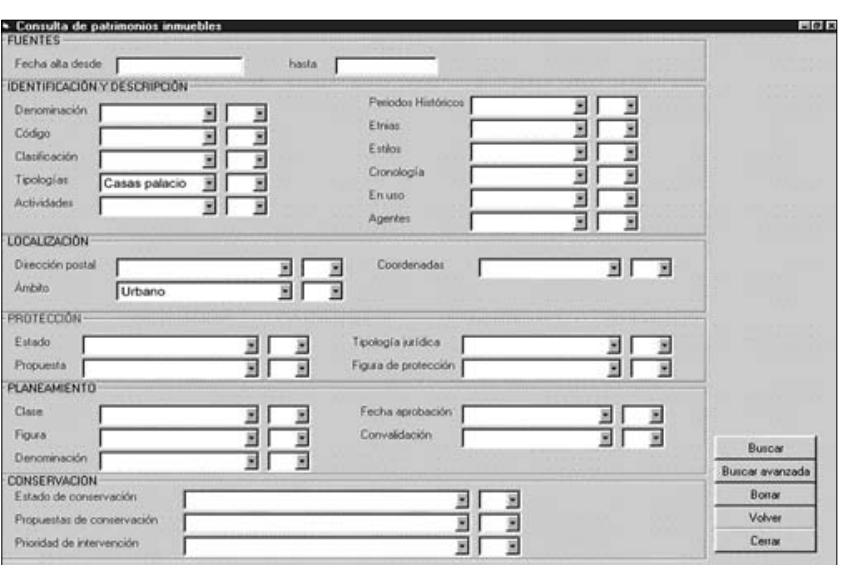

Fig. 10

Con respecto a los recursos humanos, la implantación del sistema conlleva cambios organizativos y nuevas funciones que implica, por un lado la incorporación de nuevos técnicos, que deberían coordinarse desde las unidades de información, y, por otro lado, una importante labor de formación de usuarios que se concretará en la organización de cursos de formación sobre la nueva herramienta.

Por último, la alimentación descentralizada de la aplicación conlleva la coordinación y normalización de actuaciones y procesos relacionados con la producción y carga de información de la DGBC, Delegaciones e IAPH. El objetivo es lograr que la información que se produce sobre Patrimonio Histórico se incorpore al SIPHA de una manera natural y ágil, desde el momento en que se genera. Este es el reto más importante que habrá que asumir y las unidades de información de las Delegaciones y DGBC deberían desempeñar un papel fundamental en todo este proceso.

\section{Conclusiones}

Comenzábamos esta presentación diciendo que era la primera fase del proceso de integración del Sistema de Información del Patrimonio Histórico de Andalucía. Efectivamente son aún bastantes los temas pendientes para concluir un Sistema único de Información. En la actualidad la base de datos incluye los módulos de información comunes a todo el Patrimonio Inmueble, con el desarrollo próximo de los módulos específicos se completará la aplicación. El Sistema integra la base de datos de Patrimonio Inmueble y la de Ciudades Históricas, y progresivamente se irán incorporando el resto de las aplicaciones sectoriales: las bases de datos de Patrimonio Mueble, Actividades de Interés Etnológico, Información Bibliográfica, Documental y Gráfica. Por último, para un futuro, esperemos que no muy lejano, se ha previsto la integración con el Sistema de Gestión Patrimonial. ${ }^{27}$

De acuerdo con la línea de transferencia del Sistema de Información no sólo a la Administración sino a la sociedad en general, el proyecto contemplaba el desarrollo de una aplicación con una información básica de todo el Patrimonio Inmueble de Andalucía, y que está ya disponible en Internet. ${ }^{28}$

En el futuro, el Centro de Documentación tendrá que seguir asumiendo el reto de la cualificación del Sistema con el desarrollo de nuevas herramientas para el análisis y evaluación territorial del Patrimonio Histórico y a través de la normalización y control de calidad de toda la información incorporada al Sistema desde los distintos órganos de gestión de la Red de Patrimonio Histórico. ${ }^{29}$

Para terminar una pequeña reflexión, comentamos al principio que era la segunda experiencia de integración del Centro de Documentación, y esto, en un mundo como el actual en el que suelen predominar las visiones fragmentarias y parciales de la realidad, representa, sin duda, un avance significativo. Las visiones integradoras enriquecen cualquier esfera de la actividad humana, suponen, por supuesto, esfuerzos importantes porque implican consensuar, realizar concesiones -aunque sin perder la identidad- no sólo de tipo técnico sino también de protagonismo en aras de objetivos más amplios.

\section{Notas}

I. En la elaboración del Tesauro del Patrimonio Histórico Andaluz participaron arqueólogos, historiadores, antropólogos, representantes de la Universidad y de los Museos. Tesauro de Patrimonio Histórico Andaluz, García Gutiérrez, A. (dir.), Sevilla: Junta de Andalucía; Comares, 1998.

2. 10 años para innovar desde la memoria, Sevilla: Junta de Andalucía, Instituto Andaluz del Patrimonio Histórico, 2000, p. 26.

3. Bases de Datos de Patrimonio Arquitectónico, Arqueológico, Etnológico, Patrimonio Mueble, Conjuntos Históricos, Ciudades Históricas, etc.

4. Nos referimos a las redes de información (locales, intranets, extranets, etc.) que permiten compartir la información en las organizaciones o entre las organizaciones.

5. Cornella, A.: Los recursos de información: ventaja competitiva de las empresas. Madrid, etc.: McGraw-Hill, 1994. p. I19- 120

6. Muñoz Cruz, V.: La Red de Información de Patrimonio Histórico Andaluz: un instrumento para la gestión eficaz en Bienes Culturales. En Boletín IAPH, Año VI, Nº 25, Diciembre, 1998. p. 177-178.

7. La Unidad de Información de la DGBC: balance del primer año de funcionamiento. En Boletin IAPH, N. 24, Año VI, Septiembre, 1998, p. 142-143.

8. En 1993, se inicia el diseño de la base de datos de Patrimonio Arquitectónico, partiendo de la experiencia desarrollada por el 
Centro y del análisis de otras aplicaciones de otros lugares como Cataluña e Italia. La aplicación incluye módulos de información relativos a Identificación, Localización, Descripción, Administración, Delimitación del Bien y del Entorno, Conservación e Intervenciones, Documentación, Bienes Muebles y Análisis (Pico Valimaña, R.: Patrimonio Arquitectónico en el Sistema de Información del Patrimonio Histórico Andaluz. En Boletín IAPH, Año IV, N. 17, Diciembre, 1996, p. 100-103). En 1999 se produce una renovación de la base de datos, incorporándose muchos de los avances producidos en el desarrollo del primer Prototipo de la Aplicación Integrada del Patrimonio Histórico (Tapia Martín, C.: Patrimonio Arquitectónico. La renovación del Sistema de Información SIBIA. En Boletín IAPH. Año VII. N. 28, Septiembre, 1999, p. 173-178).

9. La base de datos del Patrimonio Arqueológico de Andalucía comienza a diseñarse en 1995, en colaboración con el Servicio de Protección de la DGBC. Nace con el objetivo de la informatización del Inventario arqueológico de Andalucía aunque posteriormente la aplicación incorporará información procedente de otras fuentes de información. Para su diseño se parte de las fichas elaboradas para el Inventario Arqueológico de Andalucía e incluye módulos de información referentes a Identificación, Localización, Descripción, Conservación, Intervenciones y ubicación de materiales, Documentación, Nivel de protección e Información complementaria (González-Campos Baeza, Y.; Fernández Cacho, S.: La Base de Datos de zonas arqueológicas de Andalucía. En Boletín IAPH, Año IV, N. I 6, Septiembre, 1996, p. I I2-1 I8). Posteriormente en 1999 se incorporan a la aplicación, entre otras mejoras, nuevos módulos de información (Fernández Cacho, S.; Mondéjar Fdez. de Quincoces, P.; Díaz Iglesias, J.M.: Arqueos: un modelo andaluz de gestión de la información arqueológica. En Boletín IAPH, Año VIII, No 30, marzo, 2000, p. I43-149).

10. Para el diseño de la base de datos del Patrimonio Etnológico (1997) se parte fundamentalmente del análisis de los diferentes inventarios existentes sobre este Patrimonio y en concreto de las primeras fases del Inventario de Arquitectura Popular de la DGBC. Asimismo esta aplicación se nutre de los avances conseguidos en el diseño del Prototipo de la Aplicación Integrada de Patrimonio Histórico y aporta nuevas soluciones a las necesidades de una visión antropológica. Se estructura en los módulos de Identificación, localización y descripción, Análisis formal y físico constructivo, Análisis funcional (actividades), Análisis funcional (espacio), Conservación, Protección y Documentación (Hernández León, E; Quintero Morón, M. V.: El Patrimonio Etnológico en el Sistema de Información del Patrimonio Histórico Andaluz. En Boletín IAPH, Año VI, N. 23, Junio, 1998. p. II7-121).

1 1. La base de datos de Patrimonio Mueble comienza a diseñarse en 1993 y aunque surge para el Inventario de Bienes Muebles de la Iglesia, pronto adquiere una vocación más ambiciosa y se convierte en el sistema de información del Patrimonio Mueble de Andalucía (Martínez Montiel, L: La Base de Datos de Bienes Muebles del Patrimonio Histórico Andaluz. En Boletín IAPH, Año III, N. I O, Marzo, 1994, p. 46-49). Posteriormente en 1999. 2000 se desarrolla una aplicación integrada de Patrimonio Mueble que incorpora muchos de los avances conseguidos para el Prototipo de la Aplicación Integrada de Patrimonio Histórico (Arenillas, J. A.: Bienes Muebles, hacia un nuevo concepto en la catalogación del Patrimonio Mueble. En Boletín IAPH, Año VIII, N. 32, Septiembre, 2000, p. 200-204. Arenillas, J. A., Muñoz, V. Escalona, M. J.: Bienes Muebles, una herramienta para la catalogación del Patrimonio Arqueológico. En El Sistema de Información del Patrimonio Arqueológico de Andalucía, Sevilla: Junta de Andalucía, Comares, 200 I (en imprenta).

12. La base de datos de Conjuntos Históricos se comienza a diseñar en 1997 y se nutre de información facilitada por la Consejería de Obras Públicas y Transporte, la Consejería de Cultura el Instituto Cartográfico de Andalucía y el Instituto de Estadística de Andalucía (Pico Valimaña, R.; Pérez Humanes, M. Patrimonio Arquitectónico y Urbanístico en Andalucía: hacia la configuración de un sistema de información territorial. En Boletín IAPH, Año VI, Nº 22, Marzo, 1998. p. 106-109).
13. En 1999 se diseña GeoARQUEOS, un programa de creación y validación de coberturas digitales del Patrimonio Arqueológico de Andalucía. El programa ha supuesto un importante avance en el control de calidad de la información cartográfica y en la actualización de la información (Fernández, S.; Mondéjar, P.; Díaz, J.M.: Op. cit., p. I43-149).

14. ARQUEOSMapa une en un mismo producto información alfanumérica e información cartográfica. Permite visualizar coberturas, imprimir mapas, visualizar información básica asociada a los elementos del mapa, consultas de selección por cualquiera de las coberturas, etc. (Fernández, S.; Mondéjar, P.; Díaz, J.M.: Op. cit., p. |43-|49)

15. Tapia Martín, C. La base de datos de Ciudades Históricas Andaluzas. En Boletín IAPH, Año VIII, Nº 3I, Junio, 2000, p. |88-19|.

16. En concreto, participaron las áreas temáticas de Patrimonio Histórico ( P. Arquitectónico, P. Arqueológico, P. Etnológico, P. Mueble y Normalización de las bases de datos del P. H. ) y se contó también con la colaboración del Servicio de Información para el diseño del módulo de consulta.

17. El Prototipo se concluyó en 1999 e incluía unos módulos comunes básicos de información del Patrimonio Inmueble, Patrimonio Mueble, Información Documental e Información de la Gestión, así como el Tesauro de Patrimonio Histórico.

18. Avances tales como: tabla común de alta de bienes, cajas de lista comunes (del tesauro), módulos de información comunes (protección, documentación, localización, etc.)

19. Aunque el proceso de integración del Patrimonio Inmueble y Mueble se comenzó a la vez, sin embargo se culminó antes la integración del Patrimonio Mueble debido fundamentalmente a la complejidad del análisis integrado del Patrimonio Inmueble. Arenillas, I. A.: Op. cit., p. 200-204. Arenillas, J. A., Muñoz, V. Escalona, M. J.: Op.cit (en imprenta).

20. Muñoz Cruz, V.; Ortega, Vaquero, l.: La base de datos del Patrimonio Inmueble de Andalucía en Internet; BDI-PHA. En Boletín IAPH, Año IX, №36, Septiembre, 200 I,p.238-243.

21. Sobre el Sistema de Información de Ciudades Históricas de Andalucía puede consultarse el artículo que se publica en este mismo Boletín.

22. Las bases de datos sectoriales se habían desarrollado en Access y Visual-Basic sobre Access.

23. Ver artículo de Ciudades Históricas de este mismo Boletín y Fernández, S.; Mondéjar, P.; Díaz, J.M.: Op, cit. p. I43-149).

24. El módulo de Análisis Formal y Físico Constructivo y los módulos específicos están aún pendientes de desarrollo.

25. Véase el artículo de Ciudades Históricas de Andalucía incluido en este mismo Boletín.

26. Durante el año 2000 se enviaron formularios a las Delegaciones Provinciales y Servicios de la DGBC con objeto de conocer la situación de estos organismos para iniciar el desarrollo de la Red de Información, en concreto se pedía información sobre personal disponible, equipamiento informático, etc.

27. En la actualidad el Servicio de Informática de la Secretaría General Técnica está elaborando un Plan de Sistemas de la Consejería de Cultura que incluye el desarrollo del Sistema de Gestión Patrimonial.

28. Muñoz Cruz, V.; Ortega, Vaquero, l.: Op. cit. p. 238-243.

29. Hasta el momento la carga de información del Sistema se ha basado en la incorporación de información retrospectiva y e desarrollo de proyectos de sistematización de la información, fundamentalmente los Inventarios de Patrimonio Arqueológico, Etnológico y Bienes Muebles de la Iglesia Católica, en los que el Centro de Documentación colabora con la DGBC, en la normalización y control de calidad de la información, y otros proyectos puntuales tales como Informatización de Cementerios, Docomomo, etc. 